\title{
La escritura como compromiso El porqué de nuestra revista
}

Elvira Maritza Andino

Directora del Departamento de Antropologia UNAN-Managua

$\mathrm{E}$ 1 Departamento de Antropología de la Universidad Nacional Autónoma de Nicaragua, 1 UNAN Managua, decide la elaboración de la revista virtual Raíces como respuesta a la responsabilidad adquirida en el proceso de formación en el que está comprometido. Es importante destacar que existen suficientes motivos para realizar reflexiones antropológicas a través de la escritura y que esto nos permite compartir conocimiento, intercambiar ideas y realizar retroalimentación, a partir de diferentes puntos de vista.

La escritura es un compromiso pendiente que tenemos los antropólogos y antropólogas nicaragüenses, para divulgar los resultados de un trabajo de investigación. Dar a conocer los hallazgos de lo investigado, su análisis e interpretación significa estar dispuestos a asumir un reto: someterse a la lectura y a las críticas de los lectores, con sus diferentes experiencias y conocimientos. Esa es la valentía que todo escritor debe tener.

La revista pretende abrir el espacio sobre el quehacer de la Antropología dentro y fuera de Nicaragua, buscando similitudes y diferencias que existen en nuestra región en cuanto a producción teórica, trabajo de campo, escritura etnográfica, acompañamiento comunitario. A la vez esta iniciativa editorial representará para nosotros una gran oportunidad para darnos cuenta de cuánto hemos avanzado y cuánto nos hace falta.

Entonces tenemos el propósito de aportar de acuerdo a la construcción del conocimiento que se desarrolla, edificando a partir de las investigaciones realizadas. La revista cumple una función importante para la divulgación de las ideas en las que logramos manifestar diferentes intenciones individuales y colectivas. Se trata de escribir para documentar los procesos que se están desarrollando, entender hacia dónde se dirigen las aspiraciones, expectativas y creatividad como sólo el ser humano lo puede expresar.
¿Por qué una revista más de Antropología? Desde nuestro punto de vista, no se trata de escribir por escribir, sino de saber aportar al proceso que se está gestando en los diferentes espacios de la vida del nicaragüense, tomando en cuenta las diferentes manifestaciones de la vida diaria de la población. Escribir es la forma de regresar a la sociedad lo que se ha aprendido, para entender lo vivido, llevarlo mas allá de un acto creativo, retomarlo como una manifestación del compromiso social del etnógrafo. Entonces escribir en la revista Raíces significa asumir la obligación de reflexionar en el ejercicio académico vinculado con las comunidades.

Finalmente el significado de escribir en la revista Raíces representa ante todo un doble compromiso: frente a la academia y frente a las poblaciones, porque el antropólogo no es sólo un observador, es también un facilitador de procesos de desarrollo comunitario, un productor de ideas, un intelectual orgánico. El etnógrafo debe participar en la vida académica como un escritor activo, capaz de interpretar la realidad que lo rodea, a partir del significado que los actores sociales dan a sus experiencias. Debe ser capaz de documentar y explicar las transformaciones que constantemente interesan los procesos sociales, a partir de los diferentes contextos en los que investiga.

La importancia del formato virtual de la revista Raíces tiene que ver con la promoción de espacios de acceso gratuito a la producción científica. Frente al cambio que se observa en la actualidad en relación a los procesos de globalización de las telecomunicaciones, hemos considerado importante utilizar el potencial que internet representa para divulgar la ciencia fuera de las fronteras nacionales.

La comunidad científica internacional es cada día más interconectada, gracias al número cada vez mayor de repositorios de libre acceso, revistas virtuales, libros en formato electrónico, cursos de profesionalización online, entornos virtuales diseñados para la enseñanza, el aprendizaje, el intercambio de experiencias y conocimientos, entre otros. 
Existen cambios sustanciales en relación al manejo de la información, sobre todo en la información científica que es la que nos concierne, entonces el campo de las posibilidades para el uso de la información electrónica es de mucha importancia para el acceso y amplitud de los conocimientos que se producen con fines académicos. Información que sirve para estudiar, profundizar en el ejercicio de hacer investigación $\mathrm{y}$ aportar al desarrollo humano sostenible.

Comunicar la ciencia ha sido y sigue siendo un factor decisivo en el avance de la misma y la rapidez de circulación que permite la dimensión virtual es lo que en la actualidad imprime ese sello de vertiginosidad al desarrollo científico.
La universidad como institución académica facilita la investigación, como la actividad o función inherente a su naturaleza, y apoya la publicación de resultados de investigación con la finalidad de hacer accesible la ciencia a un público cada vez más amplio.

A partir de este primer número esperamos abrir un espacio de diálogo enriquecedor y debate con nuestros lectores y con los futuros autores que desearán contribuir con sus textos, fotografías y experiencias etnográficas al desarrollo de esta iniciativa editorial.

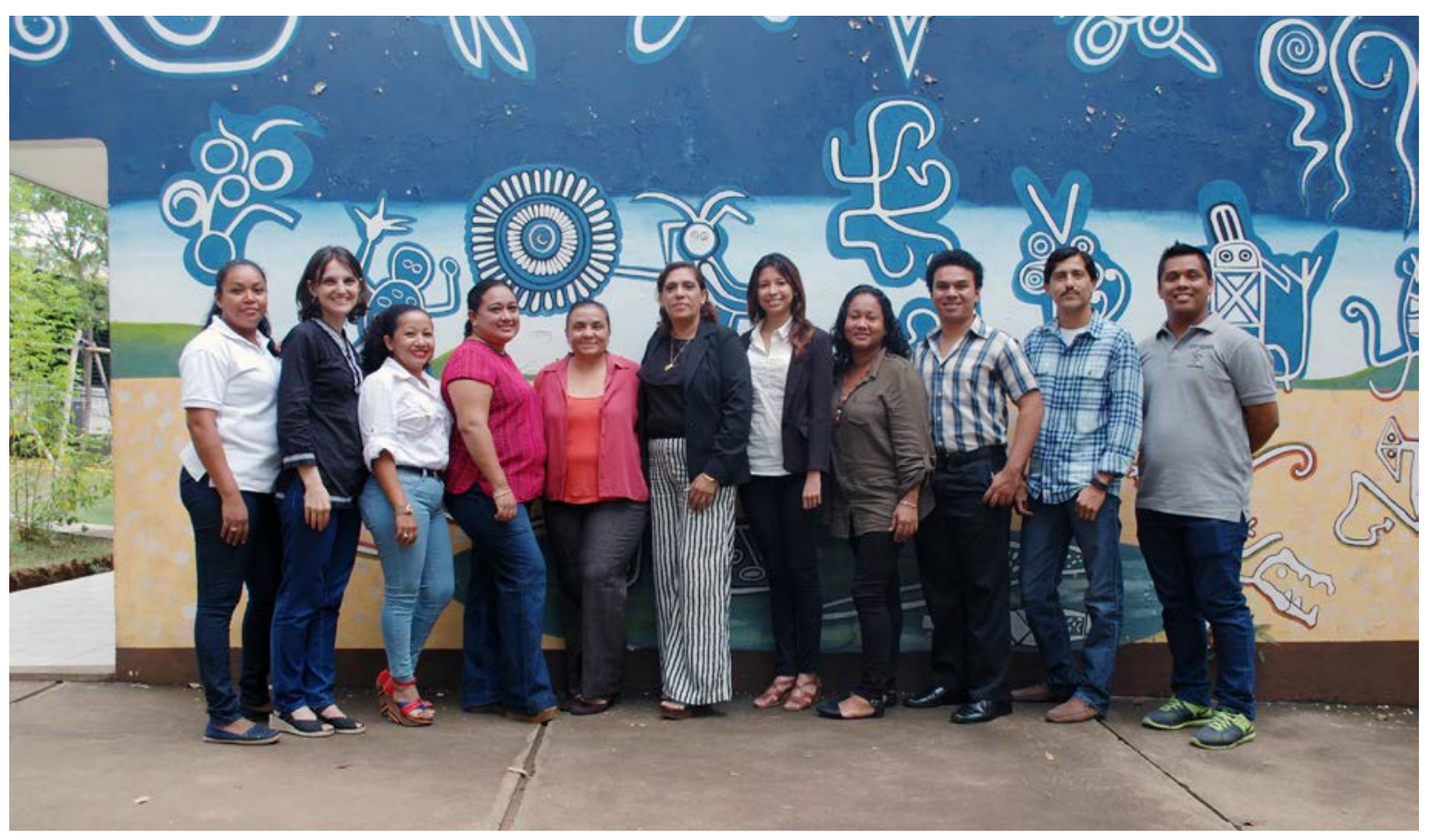

Parte del Colectivo del Departamento de Antropología. Al centro, la Directora. UNAN-Managua, diciembre del 2016

(Foto: Domingo Xavier Gutiérrez) 